\title{
Research on Purchasing Management of the Small and Medium-sized Manufacturing Enterprise Based on the Supply Chain Management Environment
}

\author{
Yan-bo $\mathrm{JIN}^{1,{ }^{*}}$ and Li-xin $\mathrm{ZHAO}^{2}$ \\ ${ }^{1}$ School of management, Changchun University, Changchun City Weixing Road No. \\ 6543, Jilin province, China \\ ${ }^{2}$ Returned overseas and expert services center, Changchun City Renmin Street \\ No.7988
}

Keywords: Small and medium manufacturing enterprise, Supply chain management, Purchasing management.

\begin{abstract}
Small and medium manufacturing enterprises in order in the fierce competition in the market based on the need to strengthen the procurement management. In this paper, supply chain management theory as a guide, analysis of the existing problems of China's small and medium manufacturing enterprises procurement management at this stage, and put forward in supply chain management of small and medium manufacturing enterprises purchasing strategy. While Changchun certain auto parts business, for example, demonstrated the feasibility of the strategy.
\end{abstract}

\section{Introduction}

Business procurement management is managing activities across the enterprise in order to protect supplies and procurement process is an important part of the whole stream. The concept of Supply chain management is originated in 1985, Michael Porter published in the "competitive advantage" in view of "value chain", after that, many scholars conducted extensive studies abroad:. Fisher (1997) think about the market product demand supply chain design to meet users demand as the goal; Martin. kristfe (2006) that the supply chain management is a holistic approach, managing upstream suppliers and downstreamcustomers, have a lower cost to the customer but more value, in the country : the famous scholar Shihua. Ma (2006) that the core idea of supply chain management is the "system" thinking view and "flow" thinking view, through the workflow capital flow and information flow efficient operation of the right products at reasonable prices, sent to the hands of consumers accurately; GuoQuan. Chen (1999), supply chain management refers to the whole supply chain system for planning, coordination, operation, control and optimization. Small and medium manufacturing enterprises as compared with the industries of large enterprises, staff size, asset size and management are relatively small economic units, poor flow of information, the lack of a sound regulatory framework, the low overall quality of procurement, supply chain and Vendors of management deficiencies. Performance Evaluation procurement unsound is a common problem currently exists. 


\section{Purchasing Management of Supply chain Environment}

\section{The Definition of the Supply Chain}

For the understanding of the supply chain, early scholars think that the supply chain is an internal process of manufacturing companies. It refers to the procurement of raw materials and parts from outside the enterprise, through production transformation and sales activities, and then passed to a procedure retailers and users. This is similar. Later, the concept of supply chain focuses on the development of relationships with other companies and the environment outside the supply chain enterprise. Currently, the concepts of supply chain focus more on the relationship between the network chains around the core business. The supply chain is not only a link to the user's supplier logistics chain, information chain, the capital chain, but also a value-added chain, can bring benefits to the relevant enterprises. The study involved five major areas of supply chain that is demand planning, logistics, supply and return, and on this basis, is subdivided into two functional areas. The basic functional areas including product engineering, product technical assurance, purchasing, production control, inventory control, warehouse management, distribution management, recycling management; auxiliary functional areas including customer service, manufacturing, design engineering, accounting, human resources, market marketing (Shihua. Ma, Yong Lin).

\section{Characteristics of Purchasing Management in Supply Chain}

Purchase Order for driving. One feature of Supply Chain Procurement management is driving to the purchase order, which is the implementation of JIT purchasing in the supply chain environment. The order-driven model of JIT, make the procurement operation closer to the market, the supply chain system respond to user demands on time, reduce inventory, cost savings, improve the logistics of speed.

Focus on extemal resource management. The idea of supply chain management is coordination, integration, synchronization, which requires procurement focus from internal to external resources management, including: (1) the establishment of a long-term mutually beneficial relation of cooperation with suppliers; (2) providing support for education and training to providers; (3) to develop supplier evaluation system and incentive mechanism; (4) Participate in product design and product quality control procedures of suppliers; (5) the establishment of a new multi-level relatively stable network of suppliers. External resource management is in favor of supply chain enterprise from internal to external integration, to enhance the core competitiveness of the entire supply chain purposes.

The establishment of quality and cooperative partnership. Yet another feature of procurement in supply chain management is the Buyer shall establish a strategic cooperative partnership with suppliers. This partnership requires buyers and suppliers enter into long-term contracts, emphasized the importance of adequate information sharing between the two parties to cooperate and coordinate with each other's behavior through cooperation and consultation, and improve operational efficiency by establishing a relationship of mutual trust and reduce transaction costs.

Lowest total cost of procurement as a starting point. Under supply chain environment, companies should be based on the lowest total cost of purchasing as the basic starting point, the price is one of the factors to consider corporate procurement, but should not be the only important consideration. In addition, companies should be concerned about the risk of 
changes in the cost of delivery of long-term, short-term costs as well as quality and supplier relationships, etc., that is focus on the total cost of the relevant purchase occurring.

\section{The Importance of the Supply Chain Procurement Management}

Effective procurement management of the supply chain reduces the total cost. Procurement costs are the main cost management. In general, the cost of manufacturing the $30 \%-80 \%$ is constituted by the purchase cost, and even some special industries accounted for more than $90 \%$. Therefore, control of procurement costs is the main channel to reduce product costs. To the enterprise of supply chain, the strengthening of corporate purchasing organization and management, use of funds for saving compressed storage costs and accelerate the turnover of working capital plays an important role.

Procurement management of supply chain is effective to protect the overall product quality level. Quality is the life of products. The procurement of materials quality directly determines the product quality is good or bad. PURCHASE, more than $60 \%$ of the product's value is provided by the supplier, while one of the characteristics of supply chain management under the Procurement Management is to establish strategic partnerships with suppliers, the establishment of such a strategic partnership, so that manufacturers can go deep into the supplier, the quality control extended to the supplier's quality control process, so that manufacturers and suppliers of quality are to be strengthened to effectively promote the improvement of the supply chain overall level of product quality (Zhi .Luo).

Good procurement management of the supply chain can reduce overall inventory level, reaction speed. Yet another feature of Purchasing Management Supply chain management is the use of the order-driven approach. This approach requires the purchasing department to continuously improve the response speed of the order, to reduce inventory costs. In supply chain, manufacturers and suppliers to establish a strategic partnership, this relationship allows manufacturers do not have to decide the size of stock, but by the supplier at the right time, the right quality, right quantity products to the right place, that is in the hands of the supplier user inventory (VMI), the use of VMI, can reduce business costs, while improving customer service levels, and the reaction speed of the entire supply chain can be improved.

\section{Management Situation of Small and Medium Manufacturing Enterprises Purchase}

In recent years, China's small and medium manufacturing enterprises have developed rapidly, occupies a very important position in the national economy. However, some small and medium manufacturing enterprises still in its early days, small-scale enterprises, business operating mechanisms are inadequate, the procurement of locating and understanding at an early stage, the procurement regulatory and supervisory control system lack detailed and specific and feasible management policy, which so that small and medium manufacturing enterprises in the procurement strategy is difficult to achieve (Zhigang.Hou.). The reasons mainly in the following areas:

\section{Procurement Concept}

Most small and medium manufacturing enterprises is the private and the private sector, Most companies will be a lot of energy to expand sales channels, increase the sales," Marketing supreme" concept of the small and medium manufacturing enterprises is firmly entrenched. The responsible people are emphasizing on marketing, purchasing contempt, existent of errors in 
understanding of procurement, the lack of awareness of the importance of procurement management, resulting in a high procurement costs, affecting the efficiency of enterprises.

\section{Aspect of Organizational Structure}

Many small and medium manufacturing enterprises set up in the organizational structure modeled on aspects of large-scale organizational structure, procurement, storage, quality control, marketing, finance, production and other departments ranging, but the division of labor is not clear responsibility and authority, the purchasing department and other departments are independent, separated, maintaining clear boundaries, resulting in buck-passing between departments, conflicts occur frequently, affecting purchasing efficiency of enterprises, making low purchasing efficiency, affect the normal functioning

\section{Supplier Management}

The author conducted a survey of the small and medium manufacturing enterprises in Jilin Province supplier relationship, found in Jilin province small and medium manufacturing enterprises signed long-term contractual relationships with suppliers less than $50 \%$, to establish strategic partnerships with suppliers is less than $10 \%$, especially small businesses and supplier relationships are essentially short-term trading relationship. This is mainly due to the lack of funds, small-scale enterprises, corporate survival is not very stable, while to the purchase price is too sensitive. This short-term increased risk of purchasing fair, there is not timely supplier delivery, service is not timely, does not match the product quantity and quality issues. In addition, the mechanism of small and medium manufacturing enterprises supplier management imperfect, under the supplier of choice in most cases rely on the experience of procurement staff, the lack of standardized vendor certification process as well as scientific and reasonable evaluation system, resulting in repeated acts of gray purchase, causing significant losses to the enterprise

\section{Procurement Modalities}

Small and medium manufacturing enterprises production scale is small, less purchasing share in procurement operations, cannot be realized as centralized purchasing as large manufacturing companies,. Also less use of advanced procurement methods like bidding, procurement and supply chain, mostly inquiry, parity and simple online-based procurement, this procurement method enables small and medium manufacturing enterprises cannot obtain price discounts given by suppliers. In addition, according to my investigation, some small and medium manufacturers tend to order-driven market, to achieve purchase orders by customer (Zhengguang .Ji Xiaohua .Liu). This procurement process for some small businesses, the order size is small, poor stability of getting orders, often have to resort to emergency procurement and purchasing, so transportation costs increase, companies are unable to obtain economies of scale.

\section{Purchasing Information}

Small and medium manufacturing enterprises due to financial, technical, management and other aspects of the subject are not introduced ERP management system for efficient process management. While most small and medium manufacturing enterprises in the use of computers and the local area network, but through the network and timely procurement of data transfer are less effective communication of information, this makes the production sector cannot communicate effectively with the purchasing department, production department cannot be 
aware of the material inventory information, warehouse cannot be aware of the order information and purchasing departments cannot control the way information and library materials, which is seriously affected the accuracy and efficiency of the implementation of corporate production activities, companies and suppliers cannot have an effective communication, suppliers unable to get the various needs of data procurement side, thus affecting the timely and accurate supply.

\section{Procurement Management Strategy of Small and Medium Manufacturing Enterprises under Supply Chain}

\section{Change Ideas to Improve Knowledge of Procurement and Supply Chain Management}

Since small and medium chain managers lack of understanding of the concept of manufacturing supply, not from the perspective of awareness of the importance of supply chain procurement management, make procurement management staying at the tactical level, which greatly affect the efficiency of procurement. Therefore, managers of small and medium manufacturing enterprises should strengthen the supply chain concept of learning to understand the supply chain management thinking, and bring the enterprise into the supply chain alliance. At the same time, small and medium manufacturing enterprise managers should change the original concept "purchase just to get money to buy things", understanding the procurement from the perspective of supply chain, learn procurement is the key link in the supply chain enterprise synchronization operation, to improve the purchasing management from tactical level to the strategic level, improve the status of purchasing management department in the enterprise, implementation of the Strategic Sourcing (Hong Liu). Only in this way, it can effectively ensure business operations, helping improve operational efficiency and competitive advantage.

\section{Optimize the Procurement Organization}

Small and medium manufacturing enterprises under the premise of establishing modern procurement management and supply chain concept, should rethink the organizational structure. Most of organizational structure in small and medium manufacturing enterprises is divided by function, this division makes all departments cannot depart from the overall interests of the enterprise, think about self-interest excessive, is not conducive to cooperation and exchanges between various departments, Create a waste of resources. For the enterprise, while The Purchasing Management Supply Chain requires to achieve seamless integration between multi-sectoral within the enterprise, through the establishment of strategic cooperative partnership with suppliers outside the enterprise, to achieve Cross-border supply chain process integration of business and sharing of critical information. This requires companies to break the traditional linear functional organization model, create cross-functional procurement team.

\section{Strengthen the Management of Suppliers}

Procurement Management of Supply Chain should focus on a good supplier management. For small and medium manufacturing enterprises, content of supplier management includes supplier selection, evaluation and relationship management in three aspects (Hao .Zhang). A good supplier management should be done: (1) selection of supplier can not only experience of procurement staff to judge, should develop a standardized supplier certification program, and 
consult the vendor's production capacity, timely delivery, product quality, price, reputation, location and other selected suppliers; (2) small and medium manufacturing enterprises should establish a comprehensive evaluation index system with partners as large enterprises, indicators content may include quality, supply, price, performance, etc. Small and medium manufacturing enterprises should regularly use the evaluation system supplier's qualitative or quantitative assessment, giving appropriate incentives to outstanding supplier, to eliminate substandard suppliers. (3) in the supply chain environment, small and medium manufacturing companies and suppliers should establish a trust mechanism, establish a win-win cooperation values, based on the exchange of information on its strategic partnerships; improving the quality of products, combined with their the cost, speed and flexible advantages, in order to ensure its geographical position in the supply chain, enhance the competitiveness of enterprises.

\section{Implementation of Join and JIT Procurement}

Small and medium manufacturing enterprises are small, less purchasing shares, unable to attract suppliers to give appropriate price discount, resulting in higher procurement costs. Small and medium manufacturing enterprises want to change this situation, we must unite with other companies for procurement, leading to higher purchase quantities to attract suppliers, to reduce costs and increase benefits (Seung-Chan Lee). For this reason, small and medium manufacturing enterprises should be done: (1) the establishment of consortiums. Small and medium manufacturing enterprises should establish purchasing alliances with other companies produce a homogeneous product supply chain to implement joint procurement. To Joint procurement of common materials, allows small and medium manufacturing enterprises set small single to large orders, raise the stakes business negotiations in terms of price, quality and services, increase their bargaining power. (2) The implementation of JIT procurement. JIT procurement, refers only when needed to order the desired product. The basic idea is at the right time, right place, in the right quantity, the right quality to provide appropriate items. The core content of purchasing management is to achieve JIT procurement under supply chain environment. Since consortiums every time purchase a large volume, and geographic proximity with suppliers, so that each vendor shipping large quantities, can ensure vehicle transportation, enables suppliers to reduce shipping costs, to ensure the timely and accurate supply, While allowing small and medium manufacturing enterprises in the supply chain do not have means of safety stock, reduce inventory risk and inventory costs.

\section{Examples of Proof}

Changchun City, Jilin Province Gear Factory is the production of a light-duty vehicle transmission business; it is a light vehicle transmission, micro-car transmission car transmission design, production, sales and service in one enterprise. The company covers an area of 112,000 square meters, construction area of 62,000 square meters, existing staff 1331 people. The main products promising micro-passenger matching CA5T70 series transmission, 1-3 tons of light trucks, buses and chassis, vans and all kinds of modified cars supporting CATS5-16, CAS5-20G, ZQCAS5-20, ZQCAS5-25, ZQCAS5-25Q7, CA5 / 6T99, CA5T100, CA5T108, CA6T115 series transmission. The company's existing supplier more than 80 , the core suppliers of more than 20 , mainly to provide the main raw material of steel, gears, bearings, housing, etc., parts. The corporate annual procurement cost of about 220 million yuan, accounting for about $60 \%$ of the total cost. Before 2008 , the company is in the 
leading position in the market. But after the 2008 financial crisis, due to the size of the market is further reduced, leading product homogeneity, so that the company's market leadership position and gradually shaken. In order to consolidate its position in the company, to expand the size of the market, the high-level research, decided to purchase the following strategies:

\section{Recognized the Importance of Procurement Ideologically}

Business leaders understand that the corporate procurement costs account for about $60 \%$ of the total cost, recognizing the importance of procurement management, while recognizing the importance of supply chain management procurement management, therefore, business leaders from the ideological emphasis on the supply chain management and procurement management, and to establish a strategic partnership with core suppliers to ensure the timely supply of raw materials and components business.

\section{Optimize the Procurement organization}

The enterprises in order to improve procurement efficiency, enhance coordination between the internal and suppliers, reducing investment and waste, through its internal investigation and study, the introduction of pre-purchasing management, That is outside the production materials procurement, general materials procurement and other traditional functions, increase the pre-purchase raw quasi-functional purchasing department, new purchasing department after the operation, has implemented a pre-purchase a car manual and automatic transmission products development projects, after completion of the project summary and analysis of the situation, confirmed Purchasing Department after optimization, the accuracy of the procurement plan has been improved, supply stability, steady improvement in resource quality, decrease cost of business investment, new product sourcing preparation period has been shortened from the previous 30-36 days to 25 days.

\section{Actively Implement the Joint Procurement}

The enterprises in order to change of the situation of high cost of procurement and the negotiating leverage gradual weakening, the enterprise form a purchasing alliance with the three $\mathrm{r}$ companies and the city's auto parts enterprises A, B and C, after the founding of the alliance to implement joint procurement of key raw materials, parts and general coordination section. The seal, for example, a seal supplier discounts quantities of 45,000 / month, purchases the company is 22,000 / month, a company of 15,000 / month, B enterprises as 06,500 / month, C companies for 16,000 / month. After the implementation of joint procurement, the total amount of the four companies reached 59,500 / month, get the supplier to give volume discounts, so that the four companies purchase price reduced by $10 \%$. After joining Purchasing Alliance, on the one hand sourcing has improved the quality of the company, on the other hand the cost of procurement has been effectively controlled. In the business material prices in May, for example, structural steel A variety of independent purchase price of 4650 yuan / ton, the joint procurement of 4,500 yuan / ton; contactor B varieties, independent purchase of 45 yuan, the joint procurement of 41 yuan; $C$ varieties of air switch, separate purchase of 17 yuan, 15 yuan joint procurement; D varieties of machine transformer, separate purchase of 98 yuan, 90 yuan for the joint procurement; seal, independent procurement $\mathrm{E}$ bonds was 3.5 yuan, joint procurement of 3 million, as shown in Table 4-1. After the implementation of joint procurement, only in May, makes the five raw materials, parts procurement total cost savings of 78,664 yuan, to bring the benefits for enterprise. 
Table1 Independent procurement and joint purchase cost comparison table in May

\begin{tabular}{|c|c|c|c|c|}
\hline Material Name & $\begin{array}{c}\text { Independent } \\
\text { purchase } \\
\text { price(yuan) }\end{array}$ & $\begin{array}{c}\text { Joint purchase } \\
\text { price(yuan) }\end{array}$ & $\begin{array}{c}\text { On } \\
\text { the amount }\end{array}$ & $\begin{array}{c}\text { Cost } \\
\text { Savings(yuan) }\end{array}$ \\
\hline Structural steel & 4650 & 4500 & $\begin{array}{c}450 \\
\text { Tons }\end{array}$ & 67500 \\
\hline Contacts & 45 & 41 & 20 Items & 80 \\
\hline air switch & 17 & 15 & 10 & 20 \\
\hline Transformer & 98 & 90 & 8 & 64 \\
\hline Seal & 3.5 & 3 & 2.2 Ten thousand & 11000 \\
\hline
\end{tabular}

\section{Conclusions}

Examples of a gear factory in Changchun can be seen, small and medium manufacturing enterprises in the fierce market competition in order to gain a foothold must increase the emphasis on supply chain management and modern procurement management. Therefore, small and medium manufacturing enterprises must change the traditional procurement management principles and practices; establish supply chain management, through the use of joint procurement, the establishment of procurement management information system, and the establishment of strategic partnerships with suppliers and other methods to solve the problems of small and medium manufacturing enterprises purchase, to further enhance the competitiveness of small and medium manufacturing purposes.

\section{Acknowledgement}

This research was financially supported by the National Science Foundation.

\section{References}

[1] J Shihua. Ma, Yong .Lin. supply chain management [M] Beijing: Higher Education Press, 2003: 2-7.

Reference to a book:

[2] Zhigang .Hou. on the supply chain management business model innovation procurement [J] Textile Leader, 2007, (11): 46-49.

[3] Hong Liu collaborative procurement and supply chain management [J]. Chinese and foreign entrepreneur's research, 2011, (7): 1-2.

[4] Hao .Zhang procurement management and inventory control [M] Beijing: Peking University Press, 2010: 22-23

[5] Seung-Chan Lee. Under the SME procurement management of the supply chain [J] Science and Technology Information, 2010, (25): 360

[6] Gaofeng .Yu Purchasing Management of Supply Chain [J]. Science and Technology Innovation Herald, 2008, (34): 165-167

[7] Zhengguang .Ji Xiaohua .Liu small machinery manufacturing enterprises to explore joint procurement model [J] Logistics Engineering and Management, 2009, (11): 65-67

[8] Zhi .Luo supplier evaluation and selection of supply chain management environment of modern business, 2011, 14: 135-136 